\title{
Functional imaging of hepatocellular carcinoma
}

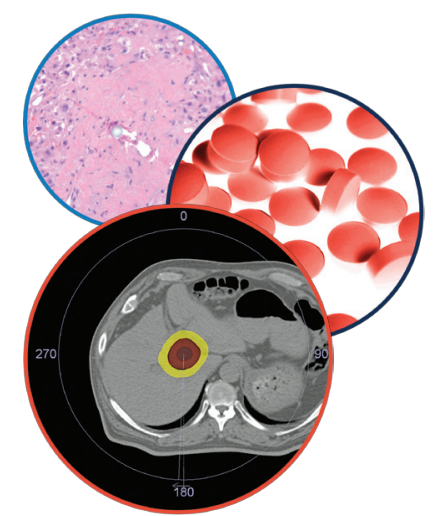

Hepatic Oncology

Tim CH Hoogenboom'1, Mark Thursz², Eric O Aboagye³ \& Rohini Sharma*,1

Practice points

- Contrast-enhanced imaging lacks sensitivity and specificity for effective hepatocellular carcinoma management.

- Imaging of tumor physiology can provide entirely new clinically relevant information.

- Targeted contrast agents, if developed further, may provide a specific method of lesion characterization.

- These agents can be of particular importance in the early stages of drug development.

- Volumetric lesion assessment and imaging of lesion viability will likely improve RECIST1.1 and mRECIST methods.

- Further prospective translational trials in these techniques are warranted.

Imaging plays a key role in the clinical management of hepatocellular carcinoma (HCC), but conventional imaging techniques have limited sensitivity in visualizing small tumors and assessing response to locoregional treatments and sorafenib. Functional imaging techniques allow visualization of organ and tumor physiology. Assessment of functional characteristics of tissue, such as metabolism, proliferation and stiffness, may overcome some of the limitations of structural imaging. In particular, novel molecular imaging agents offer a potential tool for early diagnosis of HCC, and radiomics may aid in response assessment and generate prognostic models. Further prospective research is warranted to evaluate emerging techniques and their cost-effectiveness in the context of HCC in order to improve detection and response assessment.

First draft submitted: 16 November 2015; Accepted for publication: 20 January 2016;

Published online: 29 March 2016

Hepatocellular carcinoma (HCC) is the most common primary liver tumor worldwide and the third most common cause of cancer-related death [1,2]. Most HCC arises in the context of liver cirrhosis secondary to hepatotropic viruses, alcohol excess, metabolic derangements and nonalcoholic steatohepatitis [3].

The diagnosis of HCC is based on a characteristic vascular enhancement profile using dynamic contrast-enhanced CT (DCE-CT), MRI (DCE-MRI), and in some cases, DCE-ultrasound (DCE-US) (American and European Associations for the Study of Liver Disease [AASLD and EASL] guidelines) (Figure 1) [4-6]. However, the cirrhotic liver is not homogenous but contains regenerative or dysplastic nodules, as well as HCC, presenting a challenge to conventional imaging

\section{KEYWORDS}

- CT • functional imaging

- hepatocellular carcinoma

- molecular imaging

- MRI • PET • radiomics

- ultrasound

'Department of Experimental Medicine, Imperial College London, Hammersmith Hospital, Du Cane Road, London, W12 0HS, UK 2Department of Hepatology, Imperial College NHS Trust, 10th Floor, Norfolk Place, St Mary's Hospital, London, UK

${ }^{3}$ Comprehensive Cancer Imaging Centre at Imperial College, Faculty of Medicine, Imperial College London, GN1, Ground Floor,

Commonwealth building, Hammersmith Campus, London, UK

*Author for correspondence: Tel.: +44 208383 3720; r.sharma@;imperial.ac.uk

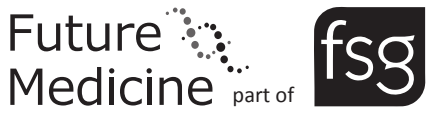




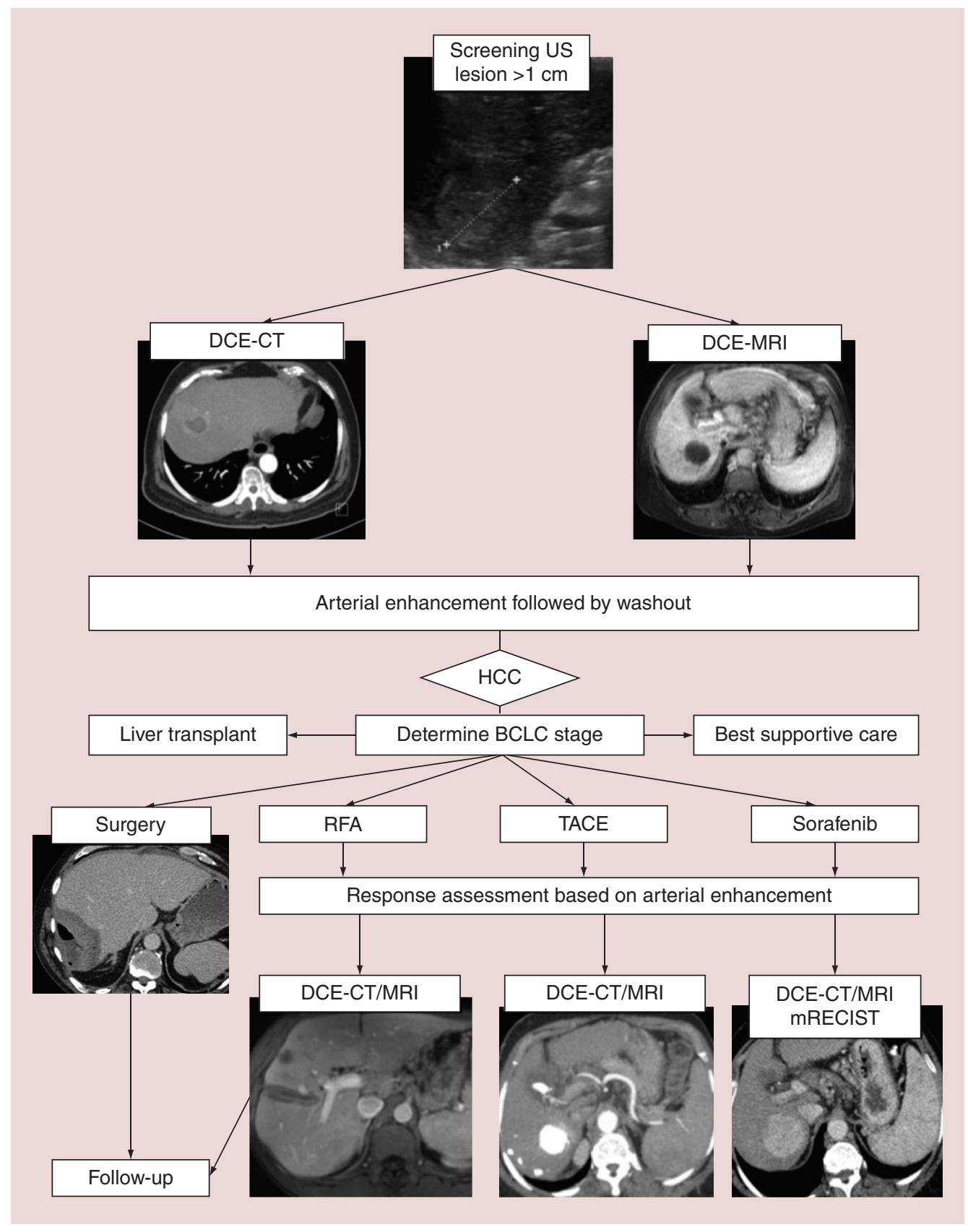

Figure 1. Flow chart for hepatocellular carcinoma management. Flow chart displaying the typical route of an HCC patient in our institution once $\mathrm{a}>1-\mathrm{cm}$ lesion is detected on US screening. BCLC: Barcelona Clinic Liver Cancer; DCE-CT: Dynamic contrast-enhanced CT; HCC: Hepatocellular carcinoma; RFA: Radiofrequency ablation; TACE: Transarterial chemoembolization; US: Ultrasound.

techniques that have limited sensitivity in differentiating various pathological processes [7]. This is of particular importance in the assessment of early stage disease, where prompt intervention translates into long-term survival. Response assessment following locoregional therapies is similarly problematic. The primary objective of these therapies is to induce necrosis, and no immediate change in tumor size is usually seen. Furthermore, the use of radiation or embolization material alters the vascular enhancement pattern of HCC, making detection of residual disease challenging. Response assessment to systemic therapies, such as the targeted agent sorafenib, is a further challenge [8]. Targeted agents produce a cytostatic rather than cytotoxic 
response, where reduction in tumor size may take months [9]. Conventional imaging response criteria WHO and RECIST1.1 [10] describe changes in tumor size based on the sum of the greatest dimensional measurement of target lesions. Therefore, WHO and RECIST1.1 are limited in assessing therapeutic response to locoregional and systemic therapies in HCC, with recent studies showing a poor correlation between clinical outcome measures and conventional radiologic response measures [11]. This is a particular concern in early-phase clinical trials setting, delaying the clinical transition of potentially efficacious agents. Introduction of modified RECIST (mRECIST) [12] and EASL criteria, that assess viable tumor, as defined by arterial enhancement, is a step change in the assessment of tumor response. However, similar to RECIST1.1 and WHO, these modified response assessment criteria are surrogates of tumor viability on representative tumor slices only, and by no means represent whole tumoranalysis. Moreover, novel drugs that target angiogenesis and perfusion may impact on contrast delivery, and mRECIST and EASL assessments.
More accurate imaging modalities are therefore urgently needed to facilitate not only clinical management but also early-phase research.

Functional imaging techniques enable the noninvasive assessment of tumor physiology, where changes in response to treatment occur earlier than changes in tumor size. These techniques may also aid in differentiating benign nodules and HCC. There are various functional imaging techniques available for both the delineation of malignant disease and therapeutic response. This review describes these techniques, discussing their application in HCC and providing an overview of the functional imaging characteristics of this disease through each imaging modality.

\section{Ultrasound}

Because of its high spatial resolution balanced against low cost and lack of radiation, biannual ultrasound (US) examination of the liver is typically used for surveillance of patients at high risk of developing HCC [4]. However, because HCC has a varied reflection pattern on US, sensitivity is low $(60 \%)$ as reported by a systematic

\section{Table 1. Detection of primary hepatocellular carcinoma with US, CT scan and MRI techniques.}

\begin{tabular}{|c|c|c|c|c|c|}
\hline \multirow[t]{2}{*}{ Study (year) } & Modality & HCC appearance & Sensitivity (\%) & Specificity (\%) & Ref. \\
\hline & \multicolumn{5}{|l|}{ US } \\
\hline Colli et al. (2006) & B-mode US & Hyper-, hypo-, iso-intense & 60 & 97 & {$[5]$} \\
\hline $\begin{array}{l}\text { Ignee et al. (2005), } \\
\text { Tanaka (1990), } \\
\text { Golli et al. (1993) }\end{array}$ & Doppler & $\begin{array}{l}\text { Hypervascular, with a } \\
\text { centripetal bloodflow } \\
\text { and/or 'basket-pattern' }\end{array}$ & - & - & {$[13-16]$} \\
\hline Alam et al. (2013) & Doppler & $\begin{array}{l}\text { Detection of portal vein } \\
\text { thrombosis }\end{array}$ & 81 & 100 & \\
\hline \multirow[t]{2}{*}{ Ding et al. (2005) } & DCE-US & $\begin{array}{l}\text { Arterial enhancement } \\
\text { followed by washout }\end{array}$ & 92 & 87 & [17] \\
\hline & \multicolumn{5}{|l|}{$C T$} \\
\hline Colli et al. (2006) & DCE-CT & $\begin{array}{l}\text { Arterial enhancement } \\
\text { followed by washout }\end{array}$ & 68 & 93 & [5] \\
\hline \multirow[t]{3}{*}{ Kim et al. (2009) } & $\begin{array}{l}\text { Perfusion } \\
\text { maps }\end{array}$ & $\begin{array}{l}\text { Higher AEF on quantitative } \\
\text { color maps }\end{array}$ & 88 & - & [18] \\
\hline & \multicolumn{5}{|l|}{ MRI } \\
\hline & $\mathrm{T} 1$ and $\mathrm{T} 2$ & $\begin{array}{l}\text { Hyper-, hypo-, iso-intense } \\
\text { or mixed }\end{array}$ & - & - & \\
\hline Colli et al. (2006) & DCE-MRI & $\begin{array}{l}\text { Arterial enhancement } \\
\text { followed by washout }\end{array}$ & 81 & 85 & [5] \\
\hline $\begin{array}{l}\text { Vandecaveye et al. } \\
\text { (2009) }\end{array}$ & DW-MRI & Restricted diffusion & 95 & 81 & [19] \\
\hline $\begin{array}{l}\text { Ichikawa et al. } \\
\text { (2010) }\end{array}$ & $\begin{array}{l}\text { Gd-EOB- } \\
\text { DTPA }\end{array}$ & $\begin{array}{l}\text { Hypointense compared } \\
\text { with surrounding liver } \\
\text { parenchyma }\end{array}$ & $68-80$ & - & {$[20]$} \\
\hline
\end{tabular}


review of 14 studies evaluating surveillance US (Table 1) [5].

\section{- Doppler \& dynamic contrast-enhanced US} Doppler US techniques visualize vascular morphology by measuring changes in US frequency that occur when a moving object reflects a US-wave, and are applied clinically with relative ease. HCC lesions are typically hypervascular, with a centripetal bloodflow [13], and some studies report a 'basket-pattern' where the lesion is cupped by blood vessels that branch inside the tumor $[14,15]$. The presence and nature of portal vein thrombosis can also be determined; with a sensitivity (81\%) and specificity (100\%) compared with DCE-CT for identifying tumor invasion [16]. DCE-US may increase the accuracy of US-assessed vascularity and hemodynamics. In DCE-US, microbubble contrast agents are used to increase the echogenicity of blood. This enables noninvasive, real-time evaluation of vascular morphology, enhancement patterns and other hemodynamics derived from time-intensity curves. Following contrast injection, HCC displays arterial enhancement followed by a 'washout', shown as an enhancement defect (Figure 2). Characterizing HCC with DCE-US based on this pattern has reasonable sensitivity (92\%) and specificity $(87 \%)$ [5,17,21]. However, small HCCs $(<2 \mathrm{~cm})$ may not have developed sufficient vascularization and often have a different enhancement pattern, similar or identical to surrounding liver tissue [7]. Moreover, intrahepatic cholangiocarcinoma and various benign lesions may also display this enhancement pattern [22] SonoVue/Lumason has received regulatory approval in a number of countries. A systematic review on DCE-US for the characterization of focal liver lesions in a cirrhotic background concluded that there was no significant difference in sensitivity and specificity between DCE-CT, -MRI and-US. The authors argue that DCE-US could potentially be applied during surveillance to further characterize screen detected lesions as it is more cost beneficial compared to CT and MRI [23]. In our institution DCE-US is often used to further characterize indeterminate lesions on CT/MRI.

DCE-US has also been investigated as a marker of therapeutic response (Table 2). DCE-US timeintensity curves, specifically area under the curve, have shown potential in the assessment of response to radiofrequency ablation (RFA) [24], transarterial chemoembolization (TACE) [25] and sorafenib [26-28]. User-dependency and low reproducibility may limit the use of DCE-US for response assessment. Introduction of timeintensity curves, and 3D techniques that allow volumetric assessment of lesions [29], may overcome these limitations as they offer a more quantitative approach. It is important to note that DCE-US response assessment is based on contrast enhancement; therefore, tumors that do not initially display arterial enhancement may not be accurately evaluated with this technique. DCE-US can also be applied to guide RFA [30,31] and 3D DCE-US in particular shows promise in this area.

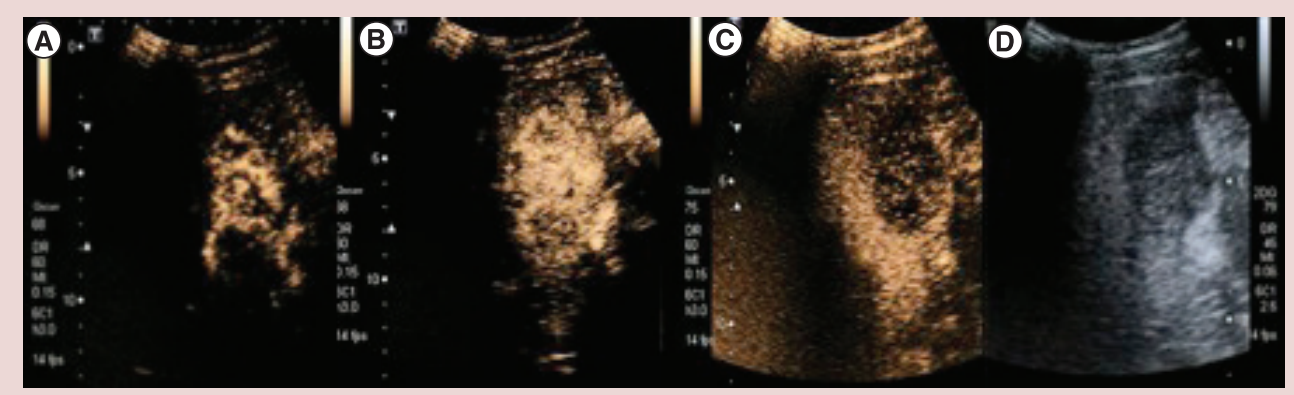

Figure 2. Dynamic contrast-enhanced ultrasound images of hepatocellular carcinoma at different time points. Dynamic contrast-enhanced ultrasound images of hepatocellular carcinoma, displaying arterial blood vessels cupping the tumor in a 'basket-pattern' (A), arterial enhancement (B) and washout (C) of a lesion in a cirrhotic liver. B-mode images with low mechanical index settings (D) allow some anatomical correlation of dynamic contrast-enhanced ultrasound images, although image quality with these settings is reduced it is necessary to avoid microbubble disruption. Images courtesy of Professor Adrian Lim, Imperial College London NHS trust. 
Table 2. Hepatocellular carcinoma response assessment by various imaging modalities.

\begin{tabular}{|c|c|c|c|c|c|}
\hline Study (year) & Modality & Treatment & Patients (n) & Result & Ref. \\
\hline $\begin{array}{l}\text { Farina et al. } \\
\text { (2009) }\end{array}$ & $\begin{array}{l}\text { DCE-US with } \\
\text { bloodpool agent }\end{array}$ & $\begin{array}{l}\text { Locoregional and } \\
\text { sorafenib }\end{array}$ & 37 & $\begin{array}{l}\text { Decrease of AUC of liver parenchyma between } 0 \text { and } \\
7 \text { days poststart of sorafenib treatment predicted } \\
\text { occurrence of adverse events. Reduction of tumor } \\
\text { AUC at day } 14 \text { was correlated with overall survival and } \\
\text { progression-free survival }\end{array}$ & {$[24-27]$} \\
\hline $\begin{array}{l}\text { Moschouris et al. } \\
\text { (2014) }\end{array}$ & & & 20 & $\begin{array}{l}1 \text { day post-RFA, TAC with high peak followed by plateau } \\
\text { indicate remaining intra- and peri-lesional tumor activity }\end{array}$ & \\
\hline $\begin{array}{l}\text { Sugimoto et al. } \\
\text { (2013) }\end{array}$ & & & 19 & $\begin{array}{l}\text { A decrease of lesion AUC by }>40 \% 1 \text { month post- } \\
\text { targeted therapy indicated nonprogression at month } 2\end{array}$ & \\
\hline Xia et al. (2008) & $\begin{array}{l}\text { DCE-US with } \\
\text { sonazoid }\end{array}$ & TACE & 43 & $\begin{array}{l}\text { Sonazoid DCE-US } 1 \text { week post-treatment predicted } \\
\text { response to TACE }\end{array}$ & [32] \\
\hline $\begin{array}{l}\text { Frampas et al. } \\
\text { (2013) }\end{array}$ & Perfusion CT & Sorafenib & 19 & $\begin{array}{l}\text { Was not able to accurately measure response in this } \\
\text { group }\end{array}$ & [26] \\
\hline $\begin{array}{l}\text { Hayashida et al. } \\
\text { (2008) }\end{array}$ & DCE-MRI & $\begin{array}{l}\text { Locoregional and } \\
\text { sorafenib }\end{array}$ & 40 & $\begin{array}{l}\text { Was more accurate at detecting arterial enhancement } \\
\text { than CT in this group mRECIST }\end{array}$ & [34] \\
\hline $\begin{array}{l}\text { Sahin et al. (2012), } \\
\text { Kokabi et al. } \\
\text { (2014) }\end{array}$ & $A D C$ values & TACE and TARE & 2018 & $\begin{array}{l}\text { TACE, increasing ADC values indicate a response. TACE, } \\
>30 \% \text { increase in ADC } 3 \text { month post-treatment }\end{array}$ & {$[36,37]$} \\
\hline Lin et al. (2012) & ${ }^{18} \mathrm{~F}-\mathrm{FDG}$ & $\begin{array}{l}\text { Surgical and } \\
\text { locoregional }\end{array}$ & 101 & $\begin{array}{l}\left({ }^{18}\right) \text { F-FDG PET was valuable in ruling out recurrence } \\
\text { disease post-treatment, meta-analysis of five studies }\end{array}$ & [38] \\
\hline
\end{tabular}

\section{- Molecular imaging with US}

Targeted molecular imaging, using specific ligands attached to microbubbles, is gaining increasing interest. While most research using targeted contrast agents is preclinical [40], Sonazoid (GE healthcare), an agent phagocytized by Kupffer cells, has shown to improve detection and characterization of liver lesions [41] and has regulatory approval in Japan. Sonazoid has been investigated as a response marker to TACE with some success [32].

There is considerable interest in developing biomarkers of angiogenesis, given its pivotal role in hepatocarcinogenesis. Integrins, a family of cell adhesion molecules, facilitate the interaction between tumor vasculature and extracellular matrix. $\alpha v \beta_{3 / 5}$-integrins are overexpressed on tumor-related endothelial cells compared with mature vessels, where they interact with components of the extracellular matrix via the tripeptide sequence arginine-glycine-aspartic acid (RGD) [42]. Utilizing the RGD sequence, Anderson et al. developed a contrast agent with high specificity for $\alpha v \beta_{3 / 5}$ in a breast cancer model [43]. This has been translated to an HCC in vivo model that could allow for the evaluation of multiple hepatic lesions in a single contrast bolus as the contrast agent an exciting concept given the lack of validated biomarkers of response to antiangiogenic therapies.

Another HCC-specific contrast agent undergoing in vitro evaluation is a monoclonal antibody to glypican-3 (GCP3) attached to polylactic-co-glycolic acid microbubbles. GPC3 is overexpressed in HCC [44], but not in healthy or cirrhotic tissue [45], thus making it suitable for lesion characterization. Anti-GCP3 strategies are also being developed in MRI and PET (discussed below) [46]. Furthermore, HAb18, that is overexpressed on tumor membrane, and 
is associated with invasion and metastasis, is also being studied as an HCC-specific contrast agent using microbubble technology $[47,48]$. How clinically feasibile these specific contrast agents will be is questionable due to cost-benefit, however, the ability to specifically target HCC may allow for therapeutic application of these agents. The use of microbubble agents for drug delivery is an active area of research, but goes beyond the scope of this review $[40,49]$.

\section{- US elastography}

US elastography (USE) quantifies lesion stiffness, a mechanical property of tissue, measured in Pascal $(\mathrm{kPa})$. Studies have shown that USE is able to distinguish between HCC and benign tissue [50,51], pathological tissue having lower elasticity than normal tissue. However, contradictory results have been reported [52,53], which may reflect reduced liver elasticity from cirrhosis, and heterogeneous elasticity profile of HCC itself. Due to the simplicity of USE, novel shear-wave techniques might prove a more robust and useful tool to apply during screening (Figure 3), though likely more in the context as a prognostic biomarker rather than a means of lesion characterization.

Important drawbacks of US-based techniques are their subjectivity, limited reproducibility and inability to assess the entire liver in a standardized manner, thus requiring additional contrast boluses, particularly in multifocal disease. Obesity, nonalcoholic steatohepatitis, abdominal air and poor patient cooperation may complicate visualization of the liver entirely (Table 1), hampering accurate response assessment. Furthermore, mRECIST/EASL evaluation is not possible with DCE-US.

\section{Multidetector CT}

\section{- Dynamic contrast-enhanced CT}

Multidetector CT imaging is widely used for the assessment of liver lesions whereby three enhancement phases are obtained; arterial, portal and delayed phase [54], with HCC displaying characteristic arterial enhancement followed by washout (Table 1) [5]. However, a significant number of lesions do not display this enhancement pattern, and biopsy is often required particularly for small 1-2 cm nodules [7,55]. DCE-CT offers good reproducibility, and is widely used to evaluate treatment response in conjunction with mRECIST. As discussed, response assessment based on mRECIST may be limited. In a retrospective study of 61 patients with HCC receiving radiotherapy, washout rather than arterial enhancement was found to be important for the evaluation of treatment response, as external beam radiotherapy can induce hyperenhancement of healthy liver parenchyma, making response assessment based on arterial enhancement difficult [33]. Response assessment following transarterial radioembolization (TARE) is also complicated. TARE can result

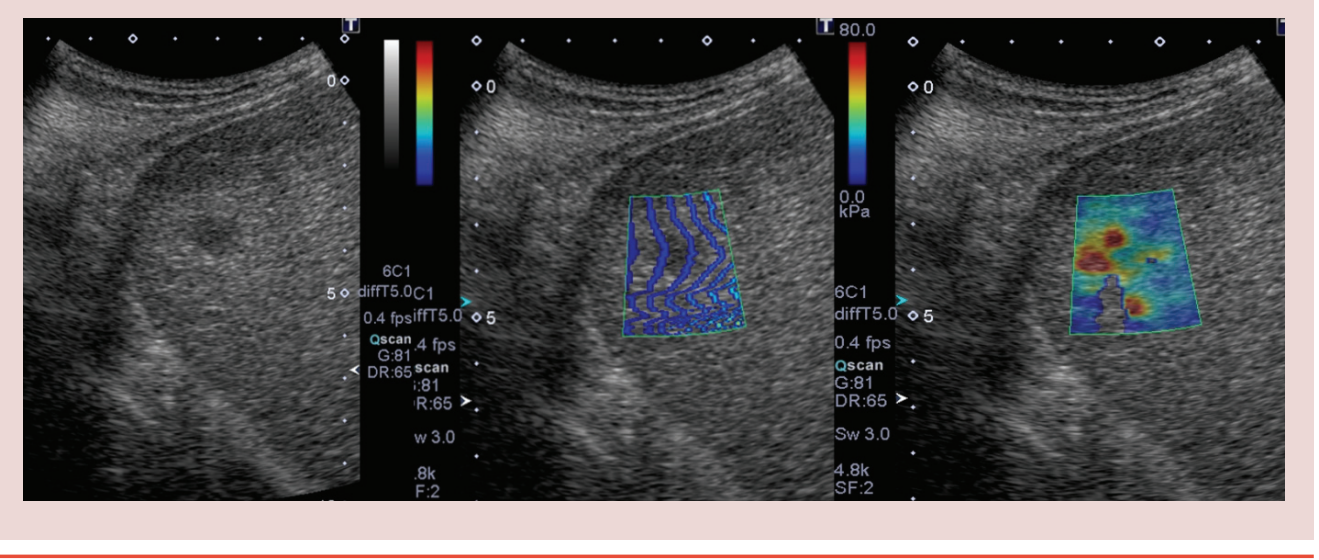

Figure 3. Shear-wave elastography of an hepatic lesion. The images display a novel shear-wave technique currently under development by Toshiba Medical Systems, applied to a hepatocellular carcinoma. Once the lesion is detected on B-mode ultrasound, shear waves are applied. As a quality control measure, a propagation map visualizes the propagation of these waves through the liver tissue. An elasticity map is then generated, displaying the regional stiffness of the selected region in $\mathrm{kPa}$. Hepatocellular carcinoma shows higher stiffness than the surrounding tissue.

Images courtesy of Professor FuminoriMoriyasu, Tokyo Medical University. 
in peritumoral edema, necrosis and hemorrhage that may cause an apparent increase in tumor size that can last up to 3-6 months post-treatment. HCCs treated with TARE exhibit a maximum RECIST response 3 months post-therapy, while absence of arterial enhancement is visible after 1 month. Correlation with other imaging methods, such as diffusion-MRI and PET, may aid in response assessment in this situation, a particular need $[56,57]$ given the increasing role of TARE in the management of HCC. Volumetric assessment of lesions has been attempted in the context of colorectal and pancreas cancer metastasis, by applying $3 \mathrm{D}$ algorithms to multidetector CT images retrospectively [58]. This study reported less inter observer variability compared with standard RECIST, however it is unclear how these algorithms would translate to lesions a cirrhotic liver.

\section{- Perfusion CT \& quantitative color maps}

By continuously scanning a volume of liver, perfusion can be assessed with excellent temporal resolution. However, clinically this technique has not borne out, with changes in perfusion parameters, such as blood flow, blood volume and mean transit time not correlating with response following sorafenib or TARE [26,59]. The high-radiation dose associated with CTP further limits its use in clinical practice. Tumor enhancement can be assessed using quantitative color maps (QCM), which can be generated with commercially available software by subtracting unenhanced images from the arterial, portal and delayed-phase scans. This enables quantitative analysis of lesion enhancement by calculating the arterial enhancement fraction [18]. HCC lesions that are iso- or hypo-enhanced on arterial phase images can display higher arterial enhancement fraction than healthy liver tissue on QCM, if they show sufficient washout during the portal or delayed phase [18]. Kim et al. proposed an improvement in diagnostic accuracy using QCM, without an increase in radiation dose $(\mathrm{n}=93)$ [18]. QCM was reported to improve response assessment following TACE compared with DCE-CT alone (Table 2) [35]. Because QCM does not increase radiation exposure, further research in the context of treatment response is warranted.

\section{- Low voltage \& dual energy CT}

Low tube voltage scanning increases tissue and contrast agent attenuation, and may be more sensitive to arterial enhancement than higher energy CT [60]. Dual energy CT can characterize tissue based on its spectral behavior, achieved by measuring tissue attenuation at different tube voltages and has been applied in the assessment of treatment response with some success [61]. The role of both low voltage scanning and dual energy imaging techniques in the clinical management of HCC requires further investigation, particularly with regards to their sensitivity and specificity when compared with standard imaging techniques.

The main disadvantage of CT compared with other imaging techniques remains radiation exposure: 25-35 mSv per DCE-CT study. Furthermore, DCE-CT has a relatively low sensitivity in diagnosing HCC (68\%) (Table 1). The use of perfusion CT, and other novel approaches such as low voltage CT [60] and dual energy CT [61] may overcome these limitations, but need further validation in prospective studies.

\section{MRI}

- Dynamic contrast-enhanced MRI

DCE-MRI allows the evaluation of hepatic nodules based on their enhancement profile, similar to DCE-US and DCE-CT [5,62-63]. Gadolinium chelates are used as contrast agents, significantly reducing $\mathrm{T} 1$ decay time, increasing signal intensity. T1 images allow visualization of the contrast agent in the extravascular-extracellular space at different time intervals enabling the assessment of the enhancement profile of any given lesion. The overall sensitivity and specificity of DCE-MRI in the context of detecting HCC is 81 and $85 \%$, respectively (Figure 4) [5]. However, sensitivity reduces with decreasing lesion size (<2 cm 50-80\%; <1 cm 3-33\%) [64].

\section{- Diffusion-weighted MRI}

DW-MRI assesses water motion within tissue and is routinely used in the clinical setting. DW-MRI images are obtained by applying balanced gradients to T2-weighted sequences. The amount of diffusion weighting can be increased or decreased by changing the 'b-value', an acquisition parameter. Signal intensity from stationary water molecules is maintained, while those that are in motion lose signal intensity. Pathological tissues typically have high signal intensity, because diffusion is often restricted, whereas healthy tissue has low signal intensity on DW-MRI. Low b-value images ( $b<150 \mathrm{~s} / \mathrm{mm}$ ) improve lesion detection compared with T2 

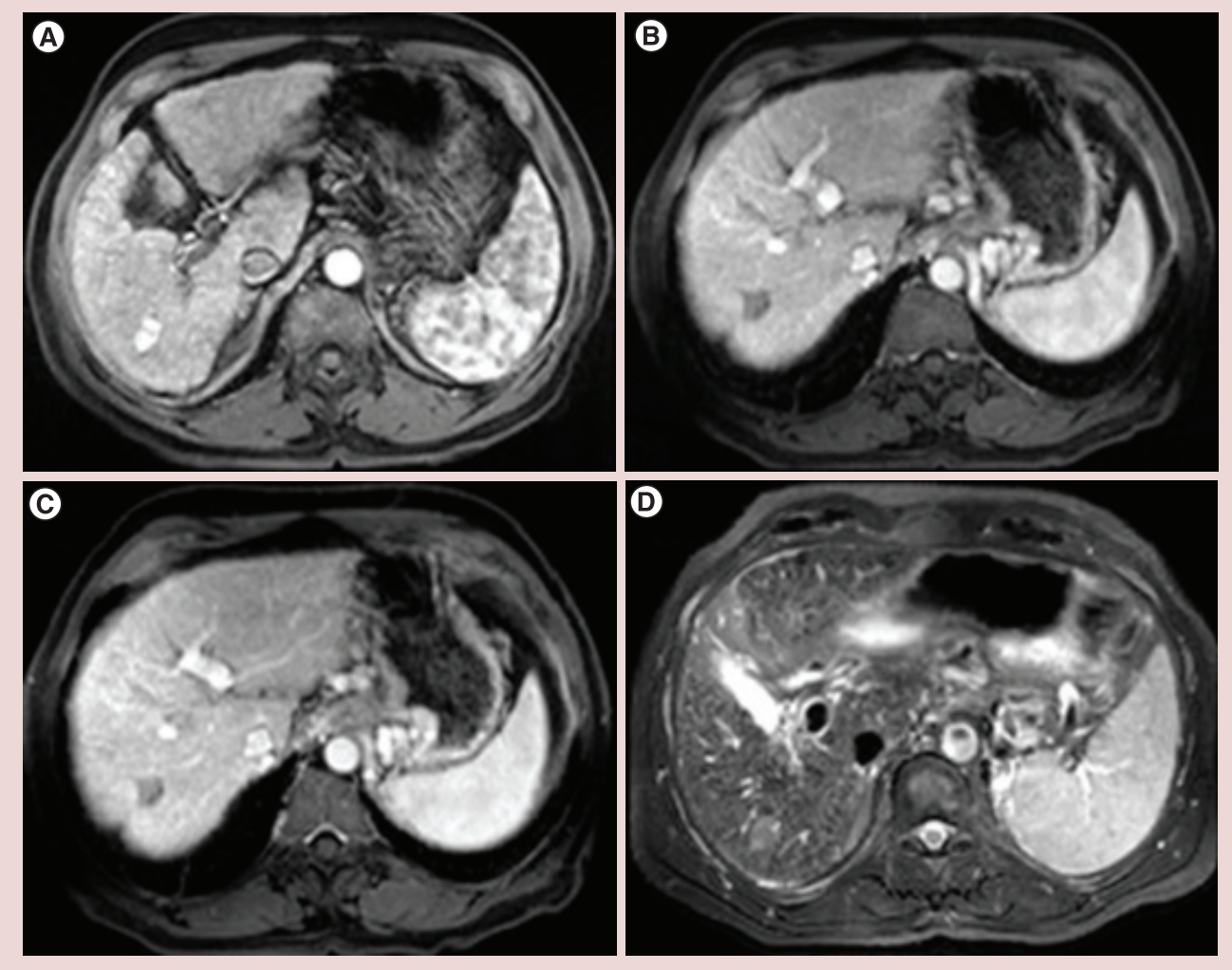

Figure 4. Typical enhancement of hepatocellular carcinoma. Arterial (A), portal (B) and delayed (C) phase images of a dynamic contrast enhanced MRI scan displaying the characteristic hepatocellular carcinoma enhancement pattern; arterial enhancement followed by washout. A T2 (D) sequence shows this lesion as slightly hyperintense compared with the surrounding liver parenchyma.

images alone, whereas high b-value images (b $<500 \mathrm{~s} / \mathrm{mm}$ ) can be used for lesion detection and characterization [65]. A study conducted in 55 patients concluded that high b-value DW-MRI (b600 s/mm) improved detection and characterization of HCC lesions compared with DCE-MRI alone (Table 1) [19].

The total displacement of water molecules is described by the apparent diffusion coefficient (ADC), generated by calculating the ADC-value for individual voxels, using multiple b-value diffusion images. ADC-maps have the added benefit of reducing T2 interference, which may be present in lesions with a long T2 decay. ADC-values can be useful for the characterization of liver lesions, with ADC cut-off values of $1.4-1.6 \times 10-\left[3 \mathrm{~mm}^{2}\right] / \mathrm{s}$ having a reported sensitivity of $74-100 \%$, and specificity of $77-100 \%$ for differentiating between benign and malignant lesions [19,65-66]. Increasing ADC-values indicate treatment response following TACE $(\mathrm{n}=74)$ and TARE $(\mathrm{n}=18)$ [36,37] (Table 2). Cirrhosis and benign cirrhotic nodules also alter diffusion in the liver, which may interfere with the interpretation of diffusion-weighted imaging and account for the relatively large range in reported sensitivity and specificity.

Intravoxel incoherent motion (IVIM) is a DW-MRI-based technique, where multiple b-values are used to separate pseudodiffusion $\left(D^{*}\right)$, perfusion fraction (f) and true molecular diffusion (D) [67]. This technique has been successfully applied to characterize liver lesions $[68,69]$. In a retrospective study $(n=42)$ comparing IVIM to ADC, low D-values indicated high-grade HCC with higher accuracy than ADC-values. Furthermore, f-values were correlated to the percentage of arterial enhancement [70]. IVIM-based imaging shows potential, and further prospective research is necessary to determine its role in the context of HCC.

\section{- MRI elastography}

MRI elastography (MRE) also measures tissue stiffness but, unlike USE, MRE allows assessment of the entire liver. Mechanical shear waves 
are applied to the liver, and the propagation of these waves is measured using phase-contrast sequences [71,72]. MRE has mainly been applied to noninvasively assess liver fibrosis [73,74], but has been used to evaluate hepatic lesions [71,75]. Malignant lesions show significantly higher stiffness using MRE compared with normal liver, benign lesions and fibrotic liver (10.1 vs $2.3 \mathrm{kPa}$, 2.7 and $5.9 \mathrm{kPa}$, respectively). A cutoff of $5 \mathrm{kPa}$ allowed for accurate distinction between benign and malignant tumors (100\%), but some overlap between malignancy and fibrosis was still observed [71]. MRE has some benefits over USE, such as its applicability in obese patients, but the high cost and technical complexity effect cost-effectiveness of the technique. MRE is not be able to differentiate between HCC, ICC or other malignant hepatic lesions. Further investigation should focus on the detection and characterization of small hepatic nodules and we feel there may be a particular role in the assessment of changes in elasticity of the liver and HCC following treatment.

\section{- Volumetric functional MRI}

mRECIST and EASL response guidelines describe changes in tumor size based on the sum of the longest axis measurement: however, this single dimension may not accurately portray the entire lesion. Feasibility of a 3D approach through semiautomated segmentation is described by Lin et al., where quantitative and volumetric EASL and RECIST (qEASL and vRECIST) were applied post -ACE [76], Volumetric assessment of DCE- and DW-MRI was superior compared with RECIST1.1, EASL, mRECIST and $\alpha$-fetoprotein levels in retrospective studies $(\mathrm{n}=144)$ [77,78]. CoronaVillalobos et al. found similar findings when applying this technique post-TACE-sorafenib therapy [79] Although more experience with these techniques is required before clinical implementation, we believe whole lesion evaluation represents a step change in response assessment of HCC.

\section{- Liver-specific contrast agents}

Contrast agents specific for liver imaging include hepatobilary agents and superparamagnetic iron oxide particles (SPIO). Hepatobiliary agents target healthy hepatocytes and are excreted through the biliary tract, while SPIO particles target the reticuloendothelial system [62]. Uptake and excretion of gadoxetic-acid-disodium
(Gd-EOB-DTPA) can be visualized dynamically, where HCC display no uptake of Gd-EOB-DTPA while normal hepatocytes do. Absorption of Gd-EOB-DTPA is mediated by organic anion - transporting polypeptide 8 (OATP8) [80] present on hepatocytes. OATP8 expression decreases with poor tumor differentiation [81], and evidence suggests uptake of Gd-EOB-DTPA correlates with a less aggressive tumor phenotype. [82]. In a multicenter trial, Gd-EOB-DTPA-MRI uptake combined with serum AFP levels, was reported to be prognostic following resection [83]. However, this was a retrospective study including multiple cohorts. Other studies report an improved detection rate using Gd-EOB-DTPA [20,84-85], and added value, especially in the detection of lesions $<1 \mathrm{~cm}$, compared with DCE-CT.

SPIO agents are phagocytized by Kupffer cells and induce local changes in the magnetic field that can be measured by T2/T2* sequences, they are not US FDA approved. Contrast is achieved as HCC contain less Kupffer cells than surrounding liver tissue. Detection rate of $\mathrm{HCC}$ can be increased using SPIO particles [86]. In a study of 114 patients with hepatic nodules, SPIO particles were reported to be useful in differentiating low-grade HCC and dysplastic nodules [87].

Contrast agents in preclinical stages of development include nanoparticles labeled with anti-GCP3 monoclonal antibody and gadolinium [88], which as previously discussed, has high specificity for HCC. This agent is currently undergoing in vitro development and may develop into a novel MR contrast agent.

Motion artefacts are a common problem in all forms of hepatic MRI scanning, especially in the presence of ascites. It is expected that, as scanning techniques improve, this will become a less limiting factor. High costs and technical complexity are further disadvantages of MRI techniques.

PET

PET imaging is a well-integrated technique in oncology, and is routinely used for diagnosis, staging and therapeutic response assessment in a number of malignancies. During PET, radiolabeled compounds are administered intravenously, at subphysiological doses, in order to assess differing characteristics of tumor biology such as proliferation, angiogenesis and apoptosis. PET has been extensively investigated in HCC with disappointing results, and in most 
centers PET imaging remains a research tool. However, this may change with the advent of novel techniques, such as immuno-PET (Table 3).

\section{- ${ }^{18} \mathrm{~F}-\mathrm{FDG}$}

Gluconeogenesis, a marker of metabolism, is increased in malignant tissue and can be visualized using ${ }^{18}$ F-FDG, the most commonly used radiotracer in oncology. High hexokinase activity, and low glucose-6-phosphatase activity, mediates the phosphorylation of ${ }^{18} \mathrm{~F}$-FDG intracellularly to ${ }^{18}$ F-FDG-6-phosphate, which becomes trapped. Hence, ${ }^{18} \mathrm{~F}-\mathrm{FDG}$ uptake reflects rate of gluconeogenesis. A number of studies have shown a correlation between high uptake of ${ }^{18} \mathrm{~F}-\mathrm{FDG}$ and high-grade tumors [92-94]. Others have indicated the prognostic value of ${ }^{18} \mathrm{~F}-\mathrm{FDG}$ in selecting patients for liver transplantation [95], locoregional treatment [96] or sorafenib [97]. However, the rate of gluconeogenesis of normal hepatocytes and HCC is similar, resulting in high background uptake, making differentiation of HCC difficult. The reduction in glucose-6-phosphatase expression is dependent on degree of differentiation in liver lesions and is not absolute [98]. Furthermore, ${ }^{18} \mathrm{~F}$-FDG uptake is increased in the presence of inflammation, a potential confounding factor as HCC develops in the presence of inflammation $[92,99]$. These factors negatively impact on the sensitivity of ${ }^{18} \mathrm{~F}$-FDG-PET in detecting intrahepatic HCC (64\%) (Table 2). ${ }^{18}$ F-FDG-PET has been reported to be inferior compared with other imaging modalities [89], and is not routinely used in clinical practice, except for the detection of extrahepatic disease in some centers [100].

\section{- ${ }^{18}$ Fluoro-thymidine}

${ }^{18} \mathrm{~F}$-FLT is a validated biomarker of proliferation, specific for malignancy [101]. Like thymidine,
${ }^{18} \mathrm{~F}$-FLT enters the cell by both sodium-dependent active nucleoside transporters and by passive diffusion, and undergoes phosphorylation by thymidine kinase-1. Phosphorylated ${ }^{18} \mathrm{~F}$-FLT is not incorporated into DNA and is trapped within the cytosol, such that the uptake of ${ }^{18} \mathrm{~F}$-FLT correlates with rate of proliferation. An initial pilot study in HCC $(n=16)$ showed promising correlation between ${ }^{18} \mathrm{~F}$-FLT uptake and cell proliferation and noninferiority compared with ${ }^{18} \mathrm{~F}$-FDG. However, there is high physiological uptake of ${ }^{18} \mathrm{~F}$-FLT within the liver, therefore making it difficult to characterize pathological hepatic lesions [102]. Kinetic spatial filtering (KSF), a temporal intensity information-based voxel clustering approach, utilizes tissue-specific time-activity curves to subtract those voxels that display a time-activity curves associated with normal tissue [103]. This leads to a reduction of background liver signal while maintaining signal from tumors. The application of KSF has been investigated for the evaluation of treatment response in liver metastases from a number of tumor types [103,104]. The same principle of KSF can be applied in the context of HCC, and may improve response assessment in the management of HCC using ${ }^{18} \mathrm{~F}$-FLT (Figure 5). Investigation of this technique in $\mathrm{HCC}$ is ongoing within our research group. We believe that ${ }^{18} \mathrm{~F}$-FLTPET with application of the KSF may offer a unique biomarker for response to targeted therapies, particularly in the setting of early drug development.

\section{- ${ }^{11} \mathrm{C}$-acetate $\&{ }^{18} \mathrm{~F}$-acetate}

Fatty acid synthesis is associated with tumor growth and invasiveness, and can be evaluated using ${ }^{11} \mathrm{C}$-acetate and ${ }^{18} \mathrm{~F}$-acetate. In a study of 32 patients with $\mathrm{HCC},{ }^{11} \mathrm{C}$-acetate had a

Table 3. Detection of primary hepatocellular carcinoma by various PET tracers.

\begin{tabular}{|c|c|c|c|c|c|}
\hline Study (year) & PET & HCC appearance & $\begin{array}{l}\text { Sensitivity } \\
\text { (\%) }\end{array}$ & $\begin{array}{l}\text { Specificity } \\
(\%)\end{array}$ & Ref. \\
\hline Wudel et al. (2003) & ${ }^{18} \mathrm{~F}-\mathrm{FDG}$ & $\begin{array}{l}\text { High uptake in poorly differentiated HCC, no significant } \\
\text { uptake in well-differentiated HCC, background uptake in } \\
\text { liver parenchyma }\end{array}$ & 64 & - & [89] \\
\hline Park et al. (2008) & ${ }^{11} \mathrm{C}$-acetate & $\begin{array}{l}\text { High uptake in well-differentiated HCC, background uptake } \\
\text { in liver parenchyma }\end{array}$ & 75 & & [90] \\
\hline Talbot et al. (2010) & ${ }^{18} \mathrm{~F}$-choline & $\begin{array}{l}\text { Increased uptake in well-differentiated HCC, low uptake in } \\
\text { poorly differentiated HCC, high background uptake in liver } \\
\text { parenchyma }\end{array}$ & 88 & 62 & [91] \\
\hline Talbot et al. (2010) & ${ }^{18} \mathrm{~F}-\mathrm{FDG}+(11) \mathrm{F}$-choline & & 94 & - & [91] \\
\hline Park et al. (2008) & ${ }^{18} \mathrm{~F}-\mathrm{FDG}+(11) \mathrm{C}$-acetate & & 86 & - & [90] \\
\hline
\end{tabular}




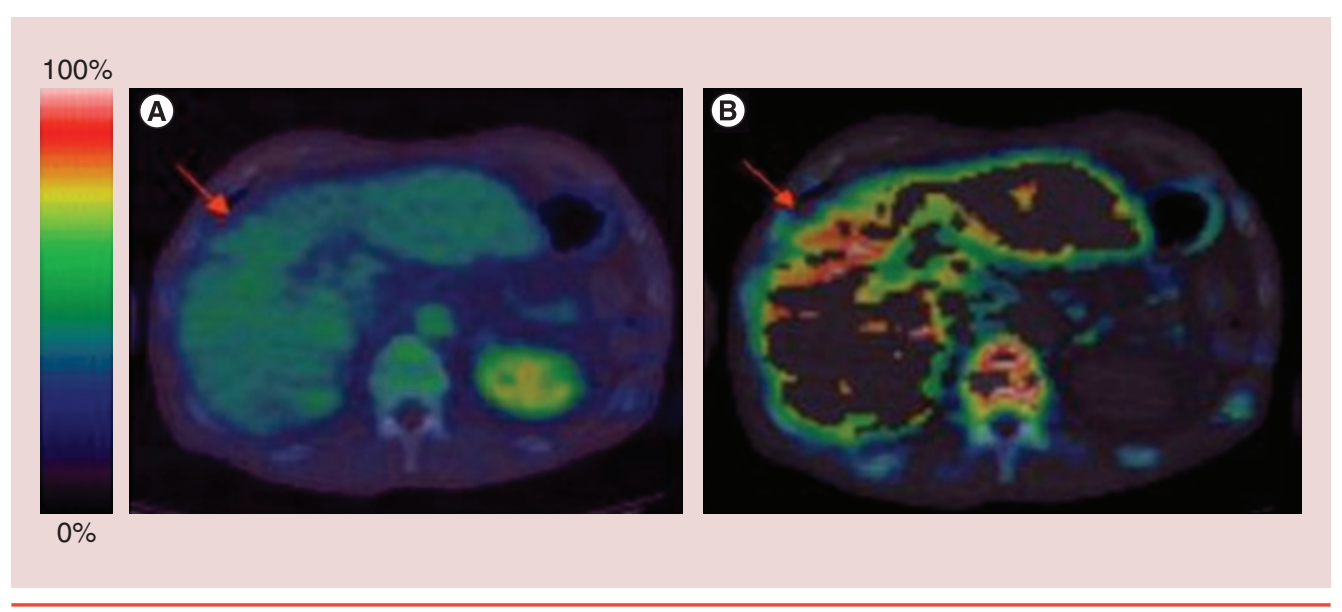

Figure 5. Kinetic spatial filtering of ${ }^{18} \mathrm{~F}-\mathrm{FLT}$ scan. $.{ }^{18} \mathrm{~F}-\mathrm{FLT}$ scan of a patient with diffuse hepatocellular carcinoma (arrow) (A), note the high background uptake of liver parenchyma, which complicates image interpretation. When kinetic spatial filtering is applied (B), it is possible to assess the diffuse hepatocellular carcinoma in this patient.

sensitivity of $87 \%$ for detecting HCC [105], and in a larger study including 110 HCC lesions, an overall sensitivity of $75 \%$ was found [90]. While encouraging, subset analysis revealed a significantly lower sensitivity (32\%) for the detection of small HCC lesions $(1-2 \mathrm{~cm}) .{ }^{18} \mathrm{~F}$-acetate was studied as an alternative to ${ }^{11} \mathrm{C}$-acetate due to its longer half-life (110 vs $20 \mathrm{~min}$ ) and more favorable biodistribution [106]. However, no difference was observed in the uptake of ${ }^{18} \mathrm{~F}$-acetate by the tumorcompared with ${ }^{18} \mathrm{~F}-\mathrm{FDG}$ [107]. The clinical value of a dual tracer approach combining ${ }^{11} \mathrm{C}$-acetate and ${ }^{18} \mathrm{~F}$-FDG has also been investigated, the rationale being that ${ }^{11} \mathrm{C}$-acetate has greater uptake in well-differentiated HCC while poorly differentiated HCC have increased uptake by ${ }^{18} \mathrm{~F}-\mathrm{FDG}$. Combined they have an overall sensitivity of $86 \%$ for detecting intrahepatic HCC, but no increase in the detection of extrahepatic disease was observed [90]. Long scan times and increased radiation dose limits the clinical applicability of a dual tracer approach.

\section{- ${ }^{11} \mathrm{C}$-choline \& ${ }^{18} \mathrm{~F}$-choline}

Choline is a substrate for phosphatidylcholine, the key phospholipid in the cell membrane. During malignant transformation, overexpression of key enzymes involved in choline metabolism are seen (e.g., choline kinase- $\alpha$ ), leading to increased phosphocholine and total choline containing compounds. Similar to ${ }^{18} \mathrm{~F}-\mathrm{FDG}$ and ${ }^{18} \mathrm{~F}$-FLT, radiolabeled choline is metabolized in the normal hepatocytes, resulting in high background uptake limiting its utility. Various studies have shown that ${ }^{11} \mathrm{C}$-choline and
${ }^{18} \mathrm{~F}$-choline have increased uptake in moderately differentiated HCC, but low uptake in poorly differentiated HCC [91,108-109]. Talbot et al. prospectively compared ${ }^{18} \mathrm{~F}$-choline with ${ }^{18} \mathrm{~F}$-FDG, and concluded a significantly higher sensitivity of ${ }^{18} \mathrm{~F}$-choline for the detection of primary HCC (88 vs 67\%) [91]. A later study emphasized the ability of ${ }^{18} \mathrm{~F}$-choline to detect extrahepatic disease, and potential to assess response in terms of local recurrence post-TACE and RFA, and progression of extrahepatic disease postsorafenib [39]. Choline tracers have mainly been studied as a dual tracer to compliment ${ }^{18} \mathrm{~F}-\mathrm{FDG}$. A study that included 78 patients with HCC found that adding ${ }^{11} \mathrm{C}$-choline increases the sensitivity of ${ }^{18} \mathrm{~F}-\mathrm{FDG}$ PET from 63 to $90 \%$ for the detection of HCC [109].

\section{- Glypican-3-targeted PET ${ }^{89} \mathrm{Zr}-\alpha \mathrm{GPC} 3$ $\&^{89} \mathrm{Zr}-\mathrm{DFO}-1 \mathrm{G} 12$}

A novel approach to visualize HCC using PET is using immuno-PET; the application of radiolabeled antibodies. ${ }^{89} \mathrm{Zr}-\alpha \mathrm{GPC} 3$ is a radiolabeled antibody that targets GCP3, as previously described [44,110]. While GPC3-targeted US and MR contrast agents have shown feasibility in vitro, ${ }^{89} \mathrm{Zr}-\alpha \mathrm{GPC} 3$ has been tested in vivo in HepG2 inoculated mice with promising results [111]. Not only was assessment of HCC feasible using ${ }^{89} \mathrm{Zr}-\alpha \mathrm{GPC} 3$, liver to lesion contrast was high. Background uptake of ${ }^{89} \mathrm{Zr}-\alpha \mathrm{GPC} 3$ may be higher in the presence of cirrhosis, however previous immunohistochemistry studies would suggest minimal uptake [45]. Similarly, the anti-GPC3 monoclonal antibody (clone 
1G12) with ${ }^{89} \mathrm{Zr}\left({ }^{89} \mathrm{Zr}-\mathrm{DFO}-1 \mathrm{G} 12\right)$ also displayed specific uptake in GPC3 positive HCC cells [112]. Monoclonal antibodies typically have a long circulation times which impacts image quality in PET imaging, and Sham et al. aimed to overcome this limitation by using $F\left(a b^{\prime}\right) 2$ fragments. Using immobilized ficin to digest $\alpha$ GPC3 they were able to create $89 \mathrm{Zr}$ - $\alpha$ GPC3$\mathrm{F}\left(\mathrm{ab}^{\prime}\right) 2$, and apply this in vivo. Their results indicate an increased tumor-to-liver contrast ratio using this method [113]. Specific uptake of ${ }^{89} \mathrm{Zr}-\alpha \mathrm{GPC} 3$ and its fragmented version should be compared with each other, in cirrhotic models if clinical translation is to be achieved.

\section{- PET/MRI}

Studies in PET/MRI have shown feasibility with encouraging results in whole-body scanning and assessment of liver metastasis [114-116]. PET/MRI allows for multiparametric evaluation of liver lesions where, for example, tracer uptake and diffusion can be assessed simultaneously, which may lead to improved response assessment [117]. This could provide an extremely useful tool in early phase clinical trials. Without CT attenuation correction, SUV measurements are underestimated in PET/MRI, but segmentation-based MR attenuation correction reduces this bias [118]. The considerable cost of PET/MRI limits routine clinical use, and we feel that the role of PET/MRI is predominantly in the research setting.

Costs of PET imaging, short half-life of some radioactive tracers and high background uptake in normal hepatocytes limit the routine use of PET. Choline, acetate, thymidine and FDGbased tracers each have been investigated in HCC with varying results, and currently their role is limited to a research setting (Tables $2 \& 3$ ). Although the clinical application of PET in HCC thus far remains limited, it has potential in the early assessment of response to targeted therapy, of particular importance, in the drug development setting [119].

\section{Radiomics \& texture analysis}

Radiomics involves the collation of quantitative imaging characteristics with the purpose of creating diagnostic and prognostic models [120]. This could be of particular importance in the context of HCC where biomarkers for patient stratification and prognosis are lacking. Aerts et al. describe tumor shape, intensity, texture and wavelet features, as characteristics used to assess tumor phenotype in lung or headand-neck malignancies based on CT imaging $(\mathrm{n}=1019)$ [121]. These features can be assessed through TA, where statistical models are applied to analyze image gray levels. TA can be applied to all modalities and has been proposed as a biomarker for tumor heterogeneity, operating on the premise that heterogeneous tumors have more or different, variations in image gray-level patterns than homogenous tumors. US-TA has shown promise in lesion characterization [122] and response assessment [123]. In a breast-cancer model responders and nonresponders were correctly identified using US-TA, after 1 week of chemotherapy, with $100 \%$ sensitivity and $93 \%$ specificity [123]. MRI-TA can characterize liver hemangiomas and cysts [124], and ${ }^{18}$ F-FLT PET TA is able to assess intratumor heterogeneity of proliferation in breast cancer, and may be used in response assessment [125]. TA is noninvasive, allowing for multiple measurements over time and allows whole lesion assessment (intratumor heterogeneity). One of the current research interests of our group is to assess the potential of MRI-TA to act as a predictive biomarker for survival and response to RFA in the context of HCC.

Quantitative imaging characteristics need to be correlated with histopathological findings and treatment outcomes [126]. A limitation of radiomics is the heterogeneity of clinical imaging protocols [120], which greatly impact the quantitative measurements. Standardized protocols should be used in prospective trials. Application of TA puts no additional burden on the patient and software development and standardized imaging protocols may lead to implementation to clinical practice. However, further prospective studies are required to correlate textural features derived from statistical models to tumor biology and verify the benefit of TA in the context of HCC.

\section{Conclusion \& future perspective}

Although a reasonable sensitivity and specificity is reported for characterizing HCC using DCE-US, DCE-CT and especially DCEMRI [5,17] based on its vascular enhancement profile, it is important to note that particularly small tumors, $<2 \mathrm{~cm}$, do not display the characteristic HCC enhancement profile [7]. Functional imaging may increase detection rate of early HCC, and aid in the characterization of hepatic nodules based on the assessment 
of physiological properties. Furthermore, these novel technologies show potential in the assessment of treatment response. This is increasingly important for clinical management of HCC, as locoregional and novel-targeted therapies cannot be accurately assessed with structural imaging alone. The incorporation of functional characteristics in RECIST (mRECIST) has shown a more accurate reflection of tumor biology, but measuring other functional characteristics and 3D lesion analysis will further improve response assessment and clinical management of HCC in the future [25,127]. Emerging HCC-specific contrast agents, such as GPC3 targeting agents, will play a large role going forward. PET ligands and multiparametric PET/MRI can prove invaluable in the drug development process and should be developed further for these purposes, while contrast agents for US and MRI may find uses in clinical practice. Staging systems of HCC will become more complex as new means of assessing and treating these lesions become available, and the clinical relevance and cost-effectiveness of each imaging method should be considered carefully before clinical implementation is considered.

Financial \& competing interests disclosure

The authors have no relevant affiliations or financial involvement with any organization or entity with a financial interest in or financial conflict with the subject matter or materials discussed in the manuscript. This includes employment, consultancies, honoraria, stock ownership or options, expert testimony, grants or patents received or pending, or royalties.

No writing assistance was utilized in the production of this manuscript.

\section{References}

Papers of special note have been highlighted as - of interest

1 Ferlay J, Shin H, Bray F, Forman D, Mathers C, Parkin DM. Estimates of worldwide burden of cancer in 2008 GLOBOCAN 2008. Int. J. Cancer 127(12), 2893-2917 (2010).

2 Forner A, Llovet JM, Bruix J. Hepatocellular carcinoma. Lancet 379 (9822), 1245-1255 (2012).

3 Everhart JE, Ruhl CE. Burden of digestive diseases in the United States part III, liver, biliary tract, and pancreas. Gastroenterology 136(4), 1134-1144 (2009).

4 European Association For The Study Of The Liver, European Organisation For Research And Treatment Of Cancer. EASL-EORTC clinical practice guidelines, management of hepatocellular carcinoma. J. Hepatol. 56(4), 908-943 (2012).

5 Colli A, Fraquelli M, Casazza G et al. Accuracy of ultrasonography, spiral CT, magnetic resonance, and alpha-fetoprotein in diagnosing hepatocellular carcinoma, a systematic review. Am. J. Gastroenterol. 101(3), 513-523 (2006).

6 Bruix J, Sherman M. American Association for the Study of Liver Diseases. Management of hepatocellular carcinoma, an update. Hepatology 53(3),1020-1022 (2011).

7 Bolondi L, Gaiani S, Celli N et al. Characterization of small nodules in cirrhosis by assessment of vascularity, the problem of hypovascular hepatocellular carcinoma. Hepatology 42(1), 27-34 (2005).
8 Faivre S, Bouattour M, Raymond E. Novel molecular therapies in hepatocellular carcinoma. Liver Int. 31, 151-160 (2011).

9 Gelmon KA, Eisenhauer EA, Harris AL, Ratain MJ, Workman P. Anticancer agents targeting signaling molecules and cancer cell environment, challenges for drug development? J. Natl Cancer Inst. 91(15), 1281-1287 (1999).

10 Eisenhauer EA, Therasse P, Bogaerts J et al. New response evaluation criteria in solid tumours, revised RECIST guideline (version 1.1). Eur. J. Cancer 45(2), 228-247 (2009).

11 Arora A, Kumar A. Treatment response evaluation and follow-up in hepatocellular carcinoma. J. Clin. Exp. Hepatol. 4(Suppl. 3), S126-S129 (2014).

12 Lencioni R, Llovet JM. Modified RECIST (mRECIST) assessment for hepatocellular carcinoma. Semin. Liver Dis. 30(1), 52-60 (2010).

13 Ignee A, Weiper D, Schuessler G, Teuber G, Faust D, Dietrich CF.

Sonographiccharacterization of hepatocellular carcinoma at time of diagnosis.

Z. Gastroenterol. 43(3), 289-294 (2005).

14 Tanaka S, Kitamura T, Fujita M, Nakanishi $\mathrm{K}$, Okuda S. Colordoppler flow imaging of liver tumors. AJR Am. J. Roentgenol. 154(3), 509-514 (1990).

15 Golli M, Mathieu D, Anglade MC, Cherqui D, Vasile N, Rahmouni A. Focal nodular hyperplasia of the liver, value of colordoppler US in association with MR imaging. Radiology 187(1), 113-117 (1993).
16 Alam S, Pervez R, Rafique S, Raheem A, Ghani M. Validity of colordoppler sonography in evaluation of malignant portal vein thrombosis in hepatocellular carcinoma. JPMI 27, 2 (2013).

17 Ding H, Wang W, Huang B et al. Imaging of focal liver lesions, low-mechanical-index real-time ultrasonography with SonoVue. J. Ultrasound Med. 24(3), 285-297 (2005).

18 Kim KW, Lee JM, Klotz E et al. Quantitative CT color mapping of the arterial enhancement fraction of the liver to detect hepatocellular carcinoma. Radiology 250 (2), 425-434 (2009).

19 Vandecaveye V, De Keyzer F, Verslype C et al. Diffusion-weighted MRI provides additional value to conventional dynamic contrastenhanced MRI for detection of hepatocellular carcinoma. Eur. Radiol. 19(10), 2456-2466 (2009).

20 Ichikawa T, Saito K, Yoshioka N et al. Detection and characterization of focal liver lesions, Ajapanese Phase III, multicenter comparison between gadoxetic acid disodium-enhanced magnetic resonance imaging and contrast-enhanced computed tomography predominantly in patients with hepatocellular carcinoma and chronic liver disease. Invest. Radiol. 45(3), 133-141 (2010).

21 Strobel D, Seitz K, Blank W et al. Contrastenhanced ultrasound for the characterization of focal liver lesions - diagnostic accuracy in clinical practice (DEGUM multicenter trial). Ultraschall. Med. 29(5), 499-505 (2008).

22 Kong W, Wang W, Huang B, Ding H, Mao F. Value of wash-in and wash-out time in the 
diagnosis between hepatocellular carcinoma and other hepatic nodules with similar vascular pattern on contrast-enhanced ultrasound. J. Gastroenterol. Hepatol. 29(3), 576-580 (2014).

23 Westwood M, Joore M, Grutters J et al. Contrast-enhanced ultrasound using SonoVue(R) (sulphur hexafluoride microbubbles) compared with contrastenhanced computed tomography and contrast-enhanced magnetic resonance imaging for the characterization of focal liver lesions and detection of liver metastases, a systematic review and cost-effectiveness analysis. Health Technol. Assess. 17(16), 1-243 (2013).

24 Farina R, Pennisi F, Mazzone G et al. Power doppler ultrasonography with time-signal intensity curves in monitoring hepatocellular carcinoma and liver metastases after intralesional therapy. Radiol. Med. 114(1), 32-41 (2009).

25 Moschouris H, Malagari K, Papadaki MG et al. mRECIST criteria and contrastenhanced US for the assessment of the response of hepatocellular carcinoma to transarterial chemoembolization. Diagn. Interv. Radiol. 20 (2), 129-135 (2014).

26 Frampas E, Lassau N, Zappa M, Vullierme MP, Koscielny S, Vilgrain V. Advanced hepatocellular carcinoma, early evaluation of response to targeted therapy and prognostic value of perfusion $\mathrm{CT}$ and dynamic contrast enhanced-ultrasound. Preliminary results. Eur. J. Radiol. 82(5), e205-e211 (2013).

27 Sugimoto K, Moriyasu F, Saito K et al. Hepatocellular carcinoma treated with sorafenib, early detection of treatment response and major adverse events by contrast-enhanced US. Liver Int. 33(4), 605-615 (2013).

28 Lassau N, Bonastre J, Kind M et al. Validation of dynamic contrast-enhanced ultrasound in predicting outcomes of antiangiogenic therapy for solid tumors, the frenchmulticenter support for innovative and expensive techniques study. Invest. Radiol. 49(12) 794-800 (2014).

29 Neshat H, Cool DW, Barker K, Gardi L, Kakani N, Fenster A. A 3D ultrasound scanning system for image guided liver interventions. Med. Phys. 40 (11), 112903 (2013).

30 Leen E, Kumar S, Khan SA et al. Contrastenhanced $3 \mathrm{D}$ ultrasound in the radiofrequency ablation of liver tumors. World J. Gastroenterol. 15(3), 289-299 (2009).

31 Meloni MF, Livraghi T, Filice C, Lazzaroni S, Calliada F, Perretti L. Radiofrequency ablation of liver tumors, the role of microbubble ultrasound contrast agents. Ultrasound Q. 22(1), 41-47 (2006).

32 Xia Y, Kudo M, Minami Y et al. Response evaluation of transcatheter arterial chemoembolization in hepatocellular carcinomas, the usefulness of sonazoidenhanced harmonic sonography. Oncology 75(Suppl. 1), 99-105 (2008).

33 Park MJ, Kim SY, Yoon SM et al. Stereotactic body radiotherapy-induced arterial hypervascularity of non-tumorous hepatic parenchyma in patients with hepatocellular carcinoma, potential pitfalls in tumor response evaluation on multiphase computed tomography. PLoS ONE 9(2), e90327 (2014).

34 Hayashida M, Ito K, Fujita T et al. Small hepatocellular carcinomas in cirrhosis, differences in contrast enhancement effects between helical CT and MR imaging during multiphasic dynamic imaging. Magn. Reson. Imaging 26(1), 65-71 (2008).

35 Lee DH, Lee JM, Klotz E et al. Detection of recurrent hepatocellular carcinoma in cirrhotic liver after transcatheter arterial chemoembolization, value of quantitative color mapping of the arterial enhancement fraction of the liver. Korean J. Radiol. 14(1), 51-60 (2013).

36 Kokabi N, Camacho JC, Xing M et al. Apparent diffusion coefficient quantification as an early imaging biomarker of response and predictor of survival following yttrium-90 radioembolization for unresectable infiltrative hepatocellular carcinoma with portal vein thrombosis. Abdom. Imaging 39(5) 969-978 (2014).

37 Sahin H, Harman M, Cinar C, Bozkaya H, Parildar M, Elmas N. Evaluation of treatment response of chemoembolization in hepatocellular carcinoma with diffusionweighted imaging on 3.0-T MR imaging. J.Vasc. Interv. Radiol. 23(2), 241-247 (2012).

38 Lin CY, Chen JH, Liang JA, Lin CC, Jeng LB, Kao CH. 18F-FDG PET or PET/CT for detecting extrahepatic metastases or recurrent hepatocellular carcinoma, a systematic review and meta-analysis. Eur. J. Radiol. 81(9), 2417-2422 (2012).

39 Bieze M, Klumpen HJ, Verheij J et al. Diagnostic accuracy of $\left({ }^{18}\right)$ F-methylcholine positron emission tomography/computed tomography for intra- and extrahepatic hepatocellular carcinoma. Hepatology 59(3), 996-1006 (2014).

40 Unnikrishnan S, Klibanov AL. Microbubbles as ultrasound contrast agents for molecular imaging, preparation and application. $A J R$ Am. J. Roentgenol. 199(2), 292-299 (2012).
41 Moriyasu F, Itoh K. Efficacy of perflubutane microbubble-enhanced ultrasound in the characterization and detection of focal liver lesions, Phase 3 multicenter clinical trial. AJR Am. J. Roentgenol. 193(1), 86-95 (2009).

42 Plow EF, Haas TA, Zhang L, Loftus J, Smith JW. Ligand binding to integrins. J. Biol. Chem. 275(29), 21785-21788 (2000).

43 Anderson CR, Hu X, Zhang $\mathrm{H}$ et al. Ultrasound molecular imaging of tumor angiogenesis with an integrin targeted microbubble contrast agent. Invest. Radiol. 46(4), 215-224 (2011).

- A key study in the context of integrin-targeted contrast agents.

44 Ho M, Kim H. Glypican-3, a new target for cancer immunotherapy. Eur. J. Cancer 47(3), 333-338 (2011).

45 Libbrecht L, Severi T, Cassiman D et al. Glypican-3 expression distinguishes small hepatocellular carcinomas from cirrhosis, dysplastic nodules, and focal nodular hyperplasia-like nodules. Am. J. Surg. Pathol. 30(11), 1405-1411 (2006).

- Another key study in the context of glypican-3-targeted contrast agents.

46 Yang J, Zeng Y, Guo DJ, Fang Z, Zhao JN, Wang ZG. Preparation and in vitro study of a high molecular weight contrast agent targeting hepatoma cells. Zhonghua Gan Zang Bing Za Zhi 21(1), 53-56 (2013).

47 Bian AN, Gao YH, Tan KB et al. Preparation of human hepatocellular carcinoma-targeted liposome microbubbles and their immunological properties. World J. Gastroenterol. 10(23), 3424-3427 (2004).

$48 \mathrm{Xu}$ J, Xu HY, Zhang Q et al. HAb18G/CD147 functions in invasion and metastasis of hepatocellular carcinoma. Mol. Cancer Res. 5(6), 605-614 (2007).

49 Bohmer MR, Klibanov AL, Tiemann K, Hall CS, Gruell H, Steinbach OC. Ultrasound triggered image-guided drug delivery. Eur. J. Radiol. 70(2), 242-253 (2009).

50 Cho SH, Lee JY, Han JK, Choi BI. Acoustic radiation force impulse elastography for the evaluation of focal solid hepatic lesions, preliminary findings. Ultrasound Med. Biol. 36(2), 202-208 (2010).

51 Zhang P, Zhou P, Tian SM, Qian Y, Deng J, Zhang L. Application of acoustic radiation force impulse imaging for the evaluation of focal liver lesion elasticity. Hepatobiliary Pancreat. Dis. Int. 12(2), 165-170 (2013).

52 Ling W, Lu Q, Lu C et al. Effects of vascularity and differentiation of hepatocellular carcinoma on tumor and liver 
stiffness, in vivo and in vitro studies. Ultrasound Med. Biol. 40(4), 739-746 (2014).

53 Gallotti A, D’Onofrio M, Romanini L, Cantisani V, PozziMucelli R. Acoustic radiation force impulse (ARFI) ultrasound imaging of solid focal liver lesions. Eur. J. Radiol. 81(3), 451-455 (2012).

54 Hwang GJ, Kim MJ, Yoo HS, Lee JT. Nodular hepatocellular carcinomas, detection with arterial-, portal-, and delayed-phase images at spiral CT. Radiology 202(2), 383-388 (1997).

55 Lee JH, Lee JM, Kim SJ et al. Enhancement patterns of hepatocellular carcinomas on multiphasicmultidetector row CT, comparison with pathological differentiation. Br. J. Radiol. 85(1017), e573-e583 (2012).

56 Singh P, Anil G. Yttrium-90 radioembolization of liver tumors, what do the images tell us? Cancer Imaging 13(4), 645-657 (2014).

57 Keppke AL, Salem R, Reddy D et al. Imaging of hepatocellular carcinoma after treatment with yttrium-90 microspheres. AJR Am. J. Roentgenol. 188(3), 768-775 (2007).

58 Rothe JH, Grieser C, Lehmkuhl L et al. Size determination and response assessment of liver metastases with computed tomography - comparison of RECIST and volumetric algorithms. Eur. J. Radiol. 82(11), 1831-1839 (2013).

59 Reiner CS, Morsbach F, Sah BR et al. Early treatment response evaluation after yttrium-90 radioembolization of liver malignancy with CT perfusion. J. Vasc. Interv. Radiol. 25(5), 747-759 (2014).

60 Marin D, Nelson RC, Samei E et al. Hypervascular liver tumors, low tube voltage, high tube current multidetector CT during late hepatic arterial phase for detection - initial clinical experience. Radiology 251(3), 771-779 (2009).

61 Lee SH, Lee JM, Kim KW et al. Dual-energy computed tomography to assess tumor response to hepatic radiofrequency ablation, Potential diagnostic value of virtual noncontrast images and iodine maps. Invest. Radiol. 46(2), 77-84 (2011).

62 Lee JM, Choi BI. Hepatocellular nodules in liver cirrhosis, MR evaluation. Abdom. Imaging 36(3), 282-289 (2011).

63 Kelekis NL, Semelka RC, Worawattanakul S et al. Hepatocellular carcinoma in north america, Amultiinstitutional study of appearance on T1-weighted, T2-weighted, and serial gadolinium-enhanced gradientecho images. AJR Am. J. Roentgenol. 170 (4), 1005-1013 (1998).
64 Willatt JM, Hussain HK, Adusumilli S, Marrero JA. MR imaging of hepatocellular carcinoma in the cirrhotic liver, challenges and controversies. Radiology 247(2), 311-330 (2008).

65 Taouli B, Koh DM. Diffusion-weighted MR imaging of the liver. Radiology 254(1), 47-66 (2010)

66 Sandrasegaran K, Tahir B, Patel A et al. The usefulness of diffusion-weighted imaging in the characterization of liver lesions in patients with cirrhosis. Clin. Radiol. 68(7), 708-715 (2013).

67 Le Bihan D, Breton E, Lallemand D, Aubin ML, Vignaud J, Laval-Jeantet M. Separation of diffusion and perfusion in intravoxel incoherent motion MR imaging. Radiology 168(2), 497-505 (1988).

68 Watanabe H, Kanematsu M, Goshima S et al. Characterizing focal hepatic lesions by free-breathing intravoxel incoherent motion MRI at 3.0 T. Acta Radiol. 55(10), 1166-1173 (2014).

69 Yamada I, Aung W, Himeno Y, Nakagawa T, Shibuya H. Diffusion coefficients in abdominal organs and hepatic lesions, evaluation with intravoxel incoherent motion echo-planar MR imaging. Radiology 210 (3), 617-623 (1999).

70 Woo S, Lee JM, Yoon JH, Joo I, Han JK, Choi BI. Intravoxel incoherent motion diffusion-weighted MR imaging of hepatocellular carcinoma, correlation with enhancement degree and histologic grade. Radiology 270 (3), 758-767 (2014).

71 Venkatesh SK, Yin M, Glockner JF et al. MR elastography of liver tumors, preliminary results. AJR Am. J. Roentgenol. 190(6), 1534-1540 (2008).

72 Mariappan YK, Glaser KJ, Ehman RL. Magnetic resonance elastography, a review. Clin. Anat. 23(5), 497-511 (2010).

73 Yin M, Talwalkar JA, Glaser KJ et al. Assessment of hepatic fibrosis with magnetic resonance elastography. Clin. Gastroenterol. Hepatol. 5(10), 1207-1213.e2 (2007).

74 Lee JE, Lee JM, Lee KB et al. Noninvasive assessment of hepatic fibrosis in patients with chronic hepatitis B viral infection using magnetic resonance elastography. Korean J. Radiol. 15(2), 210-217 (2014).

75 Doblas S, Garteiser P, Haddad N et al. Magnetic resonance elastography measurements of viscosity, a novel biomarker for human hepatic tumor malignancy. Proc. Intl. Soc. Mag. Reson. Med. 19, 389 (2011).

76 Lin M, Pellerin O, Bhagat $\mathrm{N}$ et al. Quantitative and volumetric european association for the study of the liver and response evaluation criteria in solid tumorsmeasurements, Feasibility of a semiautomated software method to assess tumor response after transcatheter arterial chemoembolization. J. Vasc. Interv. Radiol. 23(12), 1629-1637 (2012).

77 Bonekamp S, Li Z, Geschwind JF et al. Unresectable hepatocellular carcinoma, MR imaging after intraarterial therapy. Part I. Identification and validation of volumetric functional response criteria. Radiology 268(2), 420-430 (2013).

78 Bonekamp S, Halappa VG, Geschwind JF et al. Unresectable hepatocellular carcinoma, MR imaging after intraarterial therapy. Part II. Response stratification using volumetric functional criteria after intraarterial therapy. Radiology 268(2), 431-439 (2013).

- Another significant step forward in the clinical management of hepatocellular carcinoma (HCC) will be achieved through volumetric assessment of lesions during response assessment, as evidenced in this paper.

79 Corona-Villalobos C, Halappa V, Geschwind $\mathrm{J}$ et al. Volumetric assessment of tumour response using functional MR imaging in patients with hepatocellular carcinoma treated with a combination of doxorubicin-eluting beads and sorafenib. Eur. Radiol. 25(2), 380-390 (2015).

- Another paper showing that a significant step forward in the clinical management of HCC will be achieved through volumetric assessment of lesions during response assessment.

80 Kitao A, Zen Y, Matsui O et al. Hepatocellular carcinoma, signal intensity at gadoxetic acid-enhanced MR imaging - correlation with molecular transporters and histopathologic features. Radiology 256(3), 817-826 (2010).

81 Kitao A, Matsui O, Yoneda N et al. The uptake transporter OATP8 expression decreases during multistep hepatocarcinogenesis, correlation with gadoxetic acid enhanced MR imaging. Eur. Radiol. 21(10), 2056-2066 (2011).

82 Kitao A, Matsui O, Yoneda $\mathrm{N}$ et al. Hypervascular hepatocellular carcinoma, correlation between biologic features and signal intensity on gadoxetic acid-enhanced MR images. Radiology 265(3), 780-789 (2012).

83 Yamashita T, Kitao A, Matsui O et al. Gd-EOB-DTPA-enhanced magnetic resonance imaging and alpha-fetoprotein 
predict prognosis of early-stage hepatocellular carcinoma. Hepatology 60 (5), 1674-1685 (2014).

84 Raman SS, Leary C, Bluemke DA et al. Improved characterization of focal liver lesions with liver-specific gadoxetic acid disodium-enhanced magnetic resonance imaging, Amulticenter Phase 3 clinical trial. J. Comput. Assist. Tomogr. 34(2), 163-172 (2010).

85 Haimerl M, Wachtler M, Platzek I et al. Added value of gd-EOB-DTPA-enhanced hepatobiliary phase MR imaging in evaluation of focal solid hepatic lesions. $B M C$ Med. Imaging 13(41), doi:10.1186/1471-234213-41 (2013) (Epub ahead of print).

86 Tanimoto A, Kuribayashi S. Application of superparamagnetic iron oxide to imaging of hepatocellular carcinoma. Eur. J. Radiol. 58(2), 200-216 (2006).

87 Park HS, Lee JM, Kim SH et al. Differentiation of well-differentiated hepatocellular carcinomas from other hepatocellular nodules in cirrhotic liver, value of SPIO-enhanced MR imaging at 3.0 tesla. J. Magn. Reson. Imaging 29(2), 328-335 (2009).

88 Gu Y, Zeng Y, Guo DJ et al. Preparation of a glypican-3-targeting hepatocellular carcinoma MR probe and its molecular imaging in HepG2 cells. Zhonghua Gan Zang Bing Za Zhi 22(2), 142-147 (2014).

89 WudelL J Jr, Delbeke D, Morris D et al. The role of $\left({ }^{18} \mathrm{~F}\right)$ fluorodeoxyglucose positron emission tomography imaging in the evaluation of hepatocellular carcinoma. Am. Surg. 69 (2), 117-124, discussion 124-126 (2003).

90 Park JW, Kim JH, Kim SK et al. A prospective evaluation of ${ }^{18} \mathrm{~F}-\mathrm{FDG}$ and 11C-acetate PET/CT for detection of primary and metastatic hepatocellular carcinoma. J. Nucl. Med. 49(12), 1912-1921 (2008).

91 Talbot JN, Fartoux L, Balogova $\mathrm{S}$ et al. Detection of hepatocellular carcinoma with $\mathrm{PET} / \mathrm{CT}$, a prospective comparison of $18 \mathrm{~F}$-fluorocholine and ${ }^{18} \mathrm{~F}-\mathrm{FDG}$ in patients with cirrhosis or chronic liver disease. J. Nucl. Med. 51(11), 1699-1706 (2010).

92 Torizuka T, Tamaki N, Inokuma $\mathrm{T}$ et al. In vivo assessment of glucose metabolism in hepatocellular carcinoma with FDG-PET. J. Nucl. Med. 36(10), 1811-1817 (1995).

93 Lee JD, Yun M, Lee JM et al. Analysis of gene expression profiles of hepatocellular carcinomas with regard to ${ }^{18}$ uptake pattern on positron emission tomography. Eur. J. Nucl. Med. Mol. Imaging 31(12), 1621-1630 (2004).
94 Seo S, Hatano E, Higashi T et al. Fluorine-18 fluorodeoxyglucose positron emission tomography predicts tumor differentiation, P-glycoprotein expression, and outcome after resection in hepatocellular carcinoma. Clin. Cancer Res. 13(2 Pt 1), 427-433 (2007).

- Targeted contrast agents can play a significant role in both the drug development process and clinical management of HCC. In particular we would like to highlight this study, performed in the context of glypican-3-targeted contrast agents.

95 Yang SH, Suh KS, Lee HW et al. The role of $\left({ }^{18}\right)$ F-FDG-PET imaging for the selection of liver transplantation candidates among hepatocellular carcinoma patients. Liver Transpl. 12(11), 1655-1660 (2006).

96 Song MJ, Bae SH, Yoo I et al. Predictive value of (1)(8). PET/CT for transarterialchemolipiodolization of hepatocellular carcinoma. World J. Gastroenterol. 18(25), 3215-3222 (2012).

97 Lee JH, Park JY, Kim do Y et al. Prognostic value of ${ }^{18} \mathrm{~F}$-FDG PET for hepatocellular carcinoma patients treated with sorafenib. Liver Int. 31(8), 1144-1149 (2011).

98 Izuishi $\mathrm{K}$, Yamamoto $\mathrm{Y}$, Mori $\mathrm{H}$ et al. Molecular mechanisms of $\left({ }^{18} \mathrm{~F}\right)$ fluorodeoxyglucose accumulation in liver cancer. Oncol. Rep. 31(2), 701-706 (2014).

99 Shreve PD, Anzai Y, Wahl RL. Pitfalls in oncologic diagnosis with FDG PET imaging, physiologic and benign variants. Radiographics 19(1), 61-77, quiz 150-151 (1999).

100 Wolfort RM, Papillion PW, Turnage RH, Lillien DL, Ramaswamy MR, Zibari GB. Role of FDG-PET in the evaluation and staging of hepatocellular carcinoma with comparison of tumor size, AFP level, and histologic grade. Int. Surg. 95(1), 67-75 (2010)

101 Kenny L, Coombes RC, Vigushin DM, Al-Nahhas A, Shousha S, Aboagye EO. Imaging early changes in proliferation at 1 week post chemotherapy, a pilot study in breast cancer patients with 3'-deoxy-3'-(18F) fluorothymidine positron emission tomography. Eur. J. Nucl. Med. Mol. Imaging 34(9), 1339-1347 (2007).

102 Barwick T, Bencherif B, Mountz JM, Avril N. Molecular PET and PET/CT imaging of tumour cell proliferation using F-18 fluoro-L-thymidine, a comprehensive evaluation. Nucl. Med. Commun. 30 (12), 908-917 (2009).
103 Gray KR, Contractor KB, Kenny LM et al. Kinetic filtering of $\left({ }^{18} \mathrm{~F}\right)$ fluorothymidine in positron emission tomography studies. Phys. Med. Biol. 55(3), 695-709 (2010).

104 Contractor K, Challapalli A, Tomasi G et al. Imaging of cellular proliferation in liver metastasis by $\left({ }^{18} \mathrm{~F}\right)$ fluorothymidine positron emission tomography, Effect of therapy. Phys. Med. Biol. 57(11), 3419-3433 (2012).

105 Ho CL, Yu SC, Yeung DW. ${ }^{11} \mathrm{C}$-acetate PET imaging in hepatocellular carcinoma and other liver masses. J. Nucl. Med. 44(2), 213-221 (2003).

106 Ho CL, Cheung MK, Chen S et al. (18F) fluoroacetate positron emission tomography for hepatocellular carcinoma and metastases, an alternative tracer for $\left({ }^{11} \mathrm{C}\right)$ acetate? Mol. Imaging 11(3), 229-239 (2012).

107 Takemoto K, Hatano E, Nishii R et al. Assessment of $\left({ }^{18} \mathrm{~F}\right)$-fluoroacetate PET/CT as a tumor-imaging modality, preclinical study in healthy volunteers and clinical evaluation in patients with liver tumor. Ann. Nucl. Med. 28(4), 371-380 (2014).

108 Yamamoto Y, Nishiyama Y, Kameyama R et al. Detection of hepatocellular carcinoma using ${ }^{11} \mathrm{C}$-choline PET, comparison with 18F-FDG PET. J. Nucl. Med. 49 (8), 1245-1248 (2008).

109 Wu HB, Wang QS, Li BY, Li HS, Zhou WL, Wang QY. F-18 FDG in conjunction with ${ }^{11} \mathrm{C}$-choline PET/CT in the diagnosis of hepatocellular carcinoma. Clin. Nucl. Med. 36(12), 1092-1097 (2011).

110 Sham JG, Kievit FM, Grierson JR et al. Glypican-3-targeted ${ }^{89} \mathrm{Zr}$ PET imaging of hepatocellular carcinoma. J. Nucl. Med. 55(5), 799-804 (2014).

111 Sham JG, Kievit FM, Grierson JR et al. Glypican-3-targeted ${ }^{89} \mathrm{Zr}$ PET imaging of hepatocellular carcinoma. J. Nucl. Med. 55(5), 799-804 (2014).

112 Yang X, Liu H, Sun CK et al. Imaging of hepatocellular carcinoma patient-derived xenografts using ${ }^{89} \mathrm{Zr}$-labeled anti-glypican-3 monoclonal antibody. Biomaterials 35(25), 6964-6971 (2014).

113 Sham JG, Kievit FM, Grierson JR et al. Glypican-3-targeting F(ab')2 for ${ }^{89} \mathrm{Zr}$ PET of hepatocellular carcinoma. J. Nucl. Med. 55(12), 2032-2037 (2014).

114 Beiderwellen K, Gomez B, Buchbender C et al. Depiction and characterization of liver lesions in whole body $\left({ }^{18} \mathrm{~F}\right)$-FDG PET/MRI. Eur. J. Radiol. 82(11), e669-e675 (2013).

115 Quick HH, von Gall C, Zeilinger M et al. Integrated whole-body PET/MR hybrid imaging, clinical experience. Invest. Radiol. 48(5), 280-289 (2013). 
116 Reiner C, Stolzmann P, Husmann L et al. Protocol requirements and diagnostic value of PET/MR imaging for liver metastasis detection. Eur. J. Nucl. Med. Mol. Imaging 41(4), 649-658 (2014).

117 Nensa F, Beiderwellen K, Heusch P, Wetter A. Clinical applications of PET/MR, current status and future perspectives. Diagn. Interv. Radiol. 20(5), 438-447 (2014).

118 Kim JH, Lee JS, Song I, Lee DS. Comparison of segmentation-based attenuation correction methods for PET/MRI, evaluation of bone and liver standardized uptake value with oncologic PET/CT data. J. Nucl. Med. 53(12), 1878-1882 (2012).

119 Sharma R, Aboagye E. Development of radiotracers for oncology - the interface with pharmacology. Br. J. Pharmacol. 163(8), 1565-1585 (2011).
120 Kumar V, Gu Y, Basu S et al. Radiomics, the process and the challenges. Magn. Reson. Imaging 30(9), 1234-1248 (2012).

121 Aerts HJ, Velazquez ER, Leijenaar RT et al. Decoding tumour phenotype by noninvasive imaging using a quantitative radiomics approach. Nat. Commun. 5, 4006 (2014).

122 Virmani J, Kumar V, Kalra N, Khandelwal N. Characterization of primary and secondary malignant liver lesions from B-mode ultrasound. J. Digit. Imaging 26(6), 1058-1070 (2013).

123 Sadeghi-Naini A, Sannachi L, Pritchard K et al. Early prediction of therapy responses and outcomes in breast cancer patients using quantitative ultrasound spectral texture. Oncotarget 5(11), 3497-3511 (2014).

124 Mayerhoefer ME, Schima W, Trattnig S, Pinker K, Berger-Kulemann V, Ba-Ssalamah
A. Texture-based classification of focal liver lesions on MRI at 3.0 tesla, a feasibility study in cysts and hemangiomas. J. Magn. Reson. Imaging 32(2), 352-359 (2010).

125 Willaime JM, Turkheimer FE, Kenny LM, Aboagye EO. Quantification of intra-tumour cell proliferation heterogeneity using imaging descriptors of ${ }^{18} \mathrm{~F}$ fluorothymidine-positron emission tomography. Phys. Med. Biol. 58(2), 187-203 (2013)

126 Brooks F. On some misconceptions about tumor heterogeneity quantification. Eur. J. Nucl. Med. Mol. Imaging 40(8), 1292-1294 (2013).

127 Wahl RL, Jacene H, Kasamon Y, Lodge MA. From RECIST to PERCIST, evolving considerations for PET response criteria in solid tumors. J. Nucl. Med. 50 (Suppl. 1), 122S-150S (2009). 